\title{
Pengaruh Family-Work Conflict Terhadap Job Satisfaction Dengan Variabel Mediasi Work Engagement
}

\author{
Nabiilah Maulidania Fazliawan dan Yanuar \\ Program Studi S1 Manajemen, Fakultas Ekonomi dan Bisnis \\ Universitas Tarumanagara, Jakarta \\ Email: nabiilahmf@gmail.com
}

\begin{abstract}
This study aims to determine the effect of family-work conflict on job satisfaction with work engagement as mediating variable on retail employees of one company in Indonesia. Several studies previously showed that family-work conflict has no relationship with job satisfaction. In handling this gap, researcher try to add work engagement variable as mediating variable to connect the relationship and influence between family-work conflict and job satisfaction. This research uses Structural Equation Modeling (SEM) analysis as research method. A total of 100 respondents were used as research samples and used purposive sampling as sampling technique. This study shows that there is no influence between family-work conflict on job satisfaction and work engagement variable can be used as mediating variable between family-work conflict on job satisfaction.
\end{abstract}

Keywords: Family-Work Conflict, Work Engagement, Job Satisfaction, Retail employee.

Abstrak: Penelitian ini bertujuan untuk mengetahui pengaruh family-work conflict terhadap job satisfaction dengan work engagement sebagai variabel mediasi pada karyawan ritel salah satu perusahaan di Indonesia. Beberapa penelitian sebelumnya menunjukkan bahwa family-work conflict tidak memiliki hubungan dengan job satisfaction. Dalam menangani gap ini, peneliti mencoba untuk menambahkan variabel work engagement sebagai variabel mediasi untuk menjembatani hubungan serta pengaruh antara family-work conflict dengan job satisfaction. Penelitian ini menggunakan analisis Structural Equation Modeling (SEM) sebagai metode penelitian. Sebanyak 100 responden digunakan sebagai sampel penelitian dan menggunakan purposive sampling sebagai teknik sampling. Penelitian ini menunjukkan bahwa tidak terdapat pengaruh antara family-work conflict terhadap job satisfaction dan variabel work engagement dapat digunakan sebagai variabel mediasi antara family-work conflict terhadap job satisfaction.

Kata Kunci: Family-Work Conflict, Work Engagement, Job Satisfaction, Karyawan ritel.

\section{LATAR BELAKANG}

Dalam menghadapi era globalisasi yang bertumbuh dengan cukup pesat sekarang ini, perusahaan dituntut untuk memiliki sumber daya manusia yang berkompeten dengan kinerja yang baik sehingga dapat menunjang keberhasilan bisnis yang diharapkan. Dalam membuat sumber daya manusia yang berkualitas tinggi, perusahaan dituntut untuk mampu menciptakan kondisi yang dapat mendorong karyawan untuk mengembangkan dan meningkatkan kemampuan yang mereka miliki secara optimal sehingga dengan adanya hal tersebut, karyawan akan memiliki job satisfaction tersendiri yang dapat memberikan dampak positif terhadap pertumbuhan serta perkembangan perusahaan. Job satisfaction 
didefinisikan sebagai sejauh mana orang menyukai pekerjaan mereka (Singh dan Nayak, 2015). Job satisfaction memberikan peran penting dalam mendorong perusahaan dalam mengembangkan dan/atau menjalankan suatu bisnis.

Dalam beberapa tahun terakhir, beberapa penelitian mengenai family-work conflict (FWC) terhadap job satisfaction tampaknya cukup menarik perhatian, terlebih pada karyawan ritel. Family-work conflict adalah bentuk konflik antar peran di mana tuntutan umum, waktu, dan ketegangan yang diciptakan oleh keluarga dapat mengganggu pelaksanaan tanggung jawab yang terkait dengan pekerjaan (Netemeyer, Boles \& McMurrian, 1996).

Meskipun demikian, penelitian sebelumnya menemukan bahwa family-work conflict dapat memberikan pengaruh terhadap job satisfaction namun tidak ditemukan hubungan antara family-work conflict terhadap job satisfaction (Choi dan Kim, 2010). Dalam menangani gap ini, peneliti mencoba untuk menggunakan work engagement sebagai variabel mediasi. Family-work conflict merupakan salah satu faktor yang dapat memberikan pengaruh terhadap work engagement, dan work engagement merupakan salah satu faktor yang dapat memberikan pengaruh terhadap job satisfaction. Work engagement mengacu pada status pikiran positif di tempat kerja karyawan (Yeh, 2013). Karyawan yang terikat dengan pekerjaannya akan merasa bahwa dirinya dibutuhkan dalam perusahaan, mempunyai peran yang penting dalam perusahaan tersebut, serta mempunyai keinginan untuk berkontribusi dalam kesuksesan suatu perusahaan.

Untuk menjadi sukses di abad kedua puluh satu, perusahaan ritel harus mampu menarik, merekrut, dan mempertahankan tenaga kerja yang kompeten (Chung, Rutherford \& Park, 2012). Dalam mencapai hal tersebut, job satisfaction dibutuhkan karyawan agar dapat memberikan pelayanan terbaik mereka untuk menjual produk-produk yang tersedia pada suatu perusahaan ritel di tempat mereka bekerja.

\section{KAJIAN TEORI}

Ada dua teori utama yang menjelaskan mengenai job satisfaction yaitu teori dua faktor (two-factor theory) dan teori nilai (value theory) (Abdurrahman, Fadilah \& Suarsih, 2010). Two-factor theory menyatakan bahwa kepuasan dan ketidakpuasan muncul dari berbagai kelompok variabel yang berbeda. Secara umum, ketidakpuasan dapat dikaitkan dengan kondisi-kondisi di luar pekerjaan daripada pekerjaan itu sendiri. Sedangkan, value theory menyatakan bahwa job satisfaction tergantung dari tingkat hasil pekerjaan seperti imbalan yang diterima oleh seseorang dibandingkan dengan hasil yang mereka harapkan.

Terdapat beberapa teori yang dapat digunakan untuk mendukung pemahaman mengenai family-work conflict, diantaranya yaitu spillover theory, compensation theory, dan work/family border-crossing theory (Abdurrahman dkk., 2010). Spillover theory menjelaskan bahwa emosi dan perilaku seseorang dalam satu lingkup akan terbawa atau tumpah pada lingkup yang lainnya. Compensation theory merupakan suatu hubungan yang berkebalikan yang hadir antara kerja dan keluarga seperti seseorang yang mencurahkan perhatiannya dalam satu lingkup karena ketidakmampuannya memenuhi lingkup yang lain. Work/family border-crossing theory menggambarkan suatu konflik yang terjadi karena intervensi dari satu domain terhadap domain lainnya, dan memberikan kerangka berpikir bagi individu untuk menjadi border-crosser dan organisasi dengan menciptakan permeable 
aspect yang fleksibel, yang keduanya harus didorong sebagai solusi untuk mencapai keseimbangan diantara keduanya (border-blending).

Teori Konservasi Sumber Daya (Conservation of Resources/COR) digunakan sebagai landasan teoritis untuk mengembangkan hubungan antara konflik dua arah dengan work engagement. Teori COR berpendapat bahwa objek, kondisi, karakeristik pribadi, dan energy adalah sumber daya individu yang berusaha untuk memperoleh, mempertahankan, dan melindungi diri mereka (Karatepe dan Karadas, 2016).

Penelitian yang dilakukan oleh Choi dan Kim (2010) bertujuan untuk menyelidiki pengaruh prediksi konflik pekerjaan-keluarga (Work-Family Conflict), konflik keluargapekerjaan (Family-Work Conflict), fasilitasi pekerjaan-keluarga (Work-Family Facilitation), dan fasilitasi keluarga-pekerjaan (Family-Work Facilitation) terhadap job satisfaction. Penelitian ini mengungkapkan bahwa family-work conflict mempunyai hubungan negatif yang tidak signifikan terhadap job satisfaction. Penelitian ini juga didukung oleh beberapa penelitian sebelumnya yang dilakukan oleh Bhalla dan Kang (2019), Chung et al. (2012), dan Mihelič (2014) yang memiliki hasil penelitian serupa yaitu family-work conflict secara negatif dan signifikan tidak berhubungan dengan job satisfaction.

Penelitian yang dilakukan oleh Karatepe dan Karadas (2016) menunjukkan adanya pengaruh work-family conflict dan family-work conflict pada work engagement. Hasil dalam penelitian ini menyatakan bahwa karyawan frontline kurang terikat dalam pekerjaan mereka ketika mereka tidak mampu membangun keseimbangan yang sehat antara tanggung jawab pekerjaan-keluarga dan keluarga-pekerjaan mereka. Dalam penelitian ini, work engagement sepenuhnya memediasi hubungan antara work-family conflict dan life satisfaction, dan berfungsi sebagai mediator parsial antara family-work conflict pada life satisfaction. Penelitian ini juga membuktikan bahwa family-work conflict memiliki hubungan negatif yang signifikan dengan work engagement.

Penelitian yang dilakukan oleh Yeh (2013) menunjukkan bahwa adanya hubungan positif yang signifikan antara work engagement dan job satisfaction. Penelitian ini memberikan bukti bahwa karyawan yang terikat dalam pekerjaan lebih mungkin mengalami job satisfaction. Dengan kata lain, penelitian ini mengungkapkan bahwa work engagement mempunyai hubungan positif yang signifikan dengan job satisfaction. Penelitian ini juga menunjukkan bahwa keterlibatan pariwisata tidak hanya terkait langsung dengan job satisfaction karyawan frontline, tetapi juga secara tidak langsung melalui work engagement mereka. Penelitian ini juga didukung oleh Ghosh, Jawahar \& Rai (2019) yang memiliki hasil penelitian serupa. 
Fazliawan dan Yanuar: Pengaruh Family-Work Conflict Terhadap Job Satisfaction...

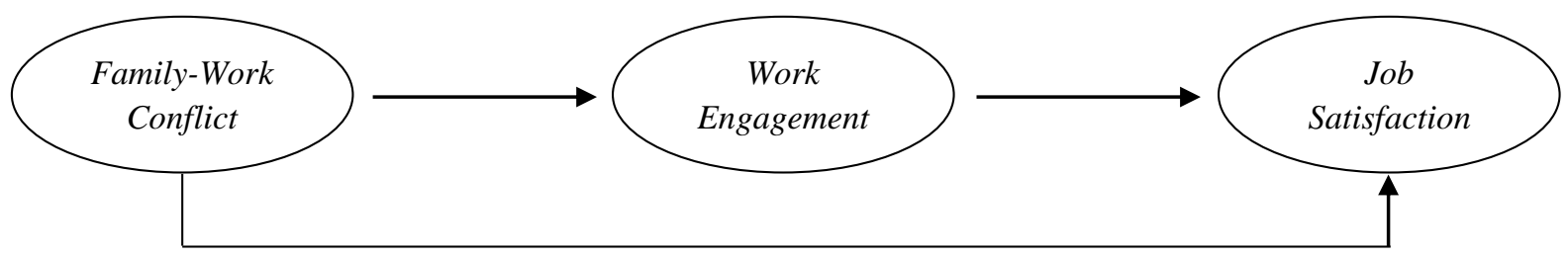

Gambar 1. Kerangka Pemikiran

Berdasarkan kerangka pemikiran di atas, berikut merupakan beberapa hipotesis yang dapat diambil:

H1: Family-Work Conflict memberikan pengaruh negatif dan signifikan terhadap Job Satisfaction.

H2: Family-Work Conflict memberikan pengaruh negatif dan signifikan terhadap Work Engagement.

H3: Work Engagement memberikan pengaruh positif dan signifikan terhadap Job Satisfaction.

H4: Work Engagement memediasi pengaruh Family-Work Conflict terhadap Job Satisfaction.

\section{METODOLOGI}

Subyek yang digunakan dalam penelitian ini yaitu karyawan pada PT Matahari Department Store Tbk Mal Ciputra Jakarta. Obyek penelitian dalam penelitian ini yaitu family-work conflict, work engagement, dan job satisfaction. Pengukuran dalam penelitian ini menggunakan pengukuran yang telah dikemukakan oleh Rotondo dan Kincaid (2008), Schaufeli, Bakker dan Salanova (2006), dan Griffin, Hogan, Lambert dan Baker (2010) yang masing-masing adalah untuk mengukur family-work conflict, work engagement, dan job satisfaction. Populasi dalam penelitian ini adalah seluruh karyawan pada PT Matahari Department Store Tbk Mal Ciputra Jakarta yang berjumlah 420 karyawan yang terdiri dari para karyawan hingga Store Manager. Sebanyak tiga variabel digunakan dalam penelitian ini dan masing-masing item atau pengukuran pada variabel tersebut berjumlah lebih dari tiga item. Hair, Black, Babin dan Anderson (2014) menyatakan bahwa ukuran sampel yang digunakan dengan adanya tiga variabel dan pengukuran variabel yang berjumlah lebih dari tiga item adalah minimum 100 sampel atau responden untuk mewakilkan populasi. Penelitian ini menggunakan analisis Structural Equation Modeling (SEM) sebagai metode penelitian dan menggunakan purposive sampling sebagai teknik sampling dalam penelitian ini. 


\section{HASIL ANALISIS DATA}

Hasil Uji Validitas

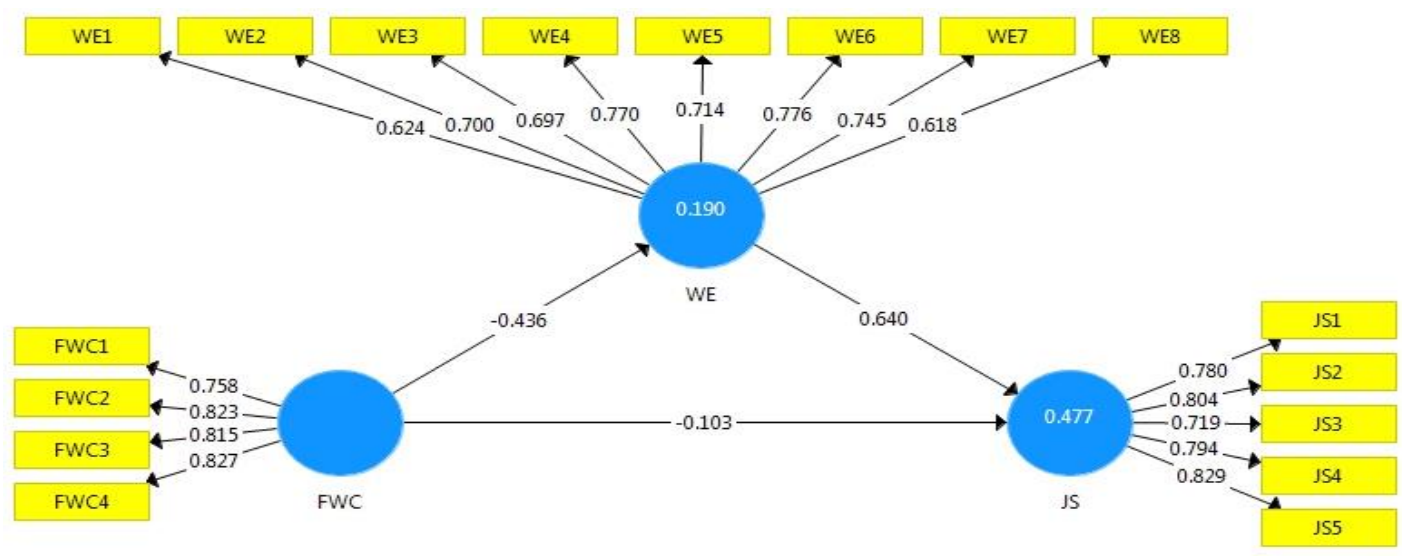

Sumber: Output Smart PLS 3

Gambar 2. Outer Loading

Berdasarkan Gambar 2, dapat disimpulkan bahwa variabel family-work conflict, work engagement, dan job satisfaction memiliki nilai outer loadings pada masing-masing indikator lebih besar dari 0,6 dimana dalam hal ini indikator-indikator tersebut dinyatakan valid (Hair et al., 2014). Indikator WE9 dihilangkan agar seluruh indikator pada masingmasing variabel dapat memberikan refleksi pada setiap variabelnya.

Tabel 1. Hasil Uji Validitas (Cross Loading)

\begin{tabular}{|c|c|c|c|c|}
\hline & $\begin{array}{c}\text { Family-Work } \\
\text { Conflict }\end{array}$ & $\begin{array}{c}\text { Work } \\
\text { Engagement }\end{array}$ & $\begin{array}{c}\text { Job } \\
\text { Satisfaction }\end{array}$ & Keterangan \\
\hline FWC1 & $\mathbf{0 , 7 5 8}$ & $-0,372$ & $-0,279$ & Valid \\
\hline FWC2 & $\mathbf{0 , 8 2 3}$ & $-0,241$ & $-0,204$ & Valid \\
\hline FWC3 & $\mathbf{0 , 8 1 5}$ & $-0,317$ & $-0,268$ & Valid \\
\hline FWC4 & $\mathbf{0 , 8 2 7}$ & $-0,418$ & $-0,413$ & Valid \\
\hline WE1 & $-0,439$ & $\mathbf{0 , 6 2 4}$ & 0,553 & Valid \\
\hline WE2 & $-0,459$ & $\mathbf{0 , 7 0 0}$ & 0,537 & Valid \\
\hline WE3 & $-0,349$ & $\mathbf{0 , 6 9 7}$ & 0,397 & Valid \\
\hline WE4 & $-0,169$ & $\mathbf{0 , 7 7 0}$ & 0,440 & Valid \\
\hline WE5 & $-0,183$ & $\mathbf{0 , 7 1 4}$ & 0,454 & Valid \\
\hline WE6 & $-0,254$ & $\mathbf{0 , 7 7 6}$ & 0,545 & Valid \\
\hline WE7 & $-0,258$ & $\mathbf{0 , 7 4 5}$ & 0,533 & Valid \\
\hline WE8 & $-0,208$ & $\mathbf{0 , 6 1 8}$ & 0,270 & Valid \\
\hline JS1 & $-0,148$ & 0,479 & $\mathbf{0 , 7 8 0}$ & Valid \\
\hline JS2 & $-0,276$ & 0,598 & $\mathbf{0 , 8 0 4}$ & Valid \\
\hline JS3 & $-0,308$ & 0,571 & $\mathbf{0 , 7 1 9}$ & Valid \\
\hline JS4 & $-0,383$ & 0,511 & $\mathbf{0 , 7 9 4}$ & Valid \\
\hline JS5 & $-0,367$ & 0,509 & $\mathbf{0 , 8 2 9}$ & Valid \\
\hline
\end{tabular}


Sumber: Output Smart PLS 3

Berdasarkan Tabel 1, dapat diketahui bahwa nilai cross loading pada masingmasing variabel memiliki nilai lebih besar daripada korelasi antar konstruk variabel laten lainnya. Ini berarti bahwa seluruh variabel dinyatakan valid (Hair Jr, Sarstedt, Hopkins \& Kuppelwieser, 2014).

\section{Hasil Uji Reliabilitas}

Tabel 2. Hasil Uji Reliabilitas (Composite Reliability)

\begin{tabular}{|l|c|c|c|}
\hline & Composite Reliability & Cronbach's Alpha & Keterangan \\
\hline Family-Work Conflict & 0,881 & 0,823 & Reliabel \\
\hline Work Engagement & 0,889 & 0,858 & Reliabel \\
\hline Job Satisfaction & 0,890 & 0,845 & Reliabel \\
\hline
\end{tabular}

Sumber: Output Smart PLS 3

Berdasarkan Tabel 2, dapat diketahui masing-masing nilai composite reliability pada masing-masing variabel adalah $0,881,0,889$, dan 0,890. Dan memiliki nilai cronbach's alpha sebesar $0,823,0,858$, dan 0,845 . Ini menyatakan bahwa seluruh variabel dapat dikatakan reliabel karena nilai composite reliability lebih besar dari 0,8 dan nilai cronbach's alpha lebih besar dari 0,6 (Hair Jr et al., 2014).

\section{Hasil Uji Coefficient of Determination (R Square)}

Tabel 3. Hasil Uji Coefficient of Determination ( $R$ Square)

\begin{tabular}{|c|c|}
\hline Variabel & $\boldsymbol{R}$ Square \\
\hline Work Engagement & 0,190 \\
\hline Job Satisfaction & 0,477 \\
\hline
\end{tabular}

Sumber: Output Smart PLS 3

Berdasarkan Tabel 3, dapat diketahui bahwa besarnya pengaruh family-work conflict terhadap work engagement sebesar 0,190 (lemah). Artinya, setiap perubahan yang ada pada family-work conflict akan memengaruhi perubahan pada work engagement sebesar 19\%. Work engagement memiliki pengaruh terhadap job satisfaction sebesar 0.477 (moderat). Artinya, setiap perubahan yang ada pada work engagement akan memengaruhi perubahan pada job satisfaction sebesar $47,7 \%$.

\section{Hasil Uji Hipotesis}

Tabel 4. Hasil Uji Hipotesis

\begin{tabular}{|l|c|c|}
\hline \multicolumn{1}{|c|}{ Variabel } & T-Statistik & P Value \\
\hline Family-Work Conflict $\rightarrow$ Job Satisfaction & 1,253 & 0,211 \\
\hline Family-Work Conflict $\rightarrow$ Work Engagement & 4,435 & 0,000 \\
\hline Work Engagement $\rightarrow$ Job Satisfaction & 7,094 & 0,000 \\
\hline $\begin{array}{l}\text { Family-Work Conflict } \rightarrow \text { Work Engagement } \rightarrow \text { Job } \\
\text { Satisfaction }\end{array}$ & 3,687 & 0,000 \\
\hline
\end{tabular}


Sumber: Output Smart PLS 3

Berdasarkan Tabel 4, dapat disimpulkan hasil dari beberapa hipotesis, yaitu:

H1: Family-Work Conflict memberikan pengaruh negatif dan signifikan terhadap Job Satisfaction.

Berdasarkan hasil uji hipotesis pada Tabel 4, dapat diketahui bahwa variabel family-work conflict terhadap job satisfaction memiliki nilai $\mathrm{T}$ Statistik sebesar 1,253 dengan nilai $P$ Value sebesar 0,211, maka $H 1$ ditolak karena nilai T Statistik lebih kecil dari nilai $\mathrm{T}$ Tabel yaitu sebesar 1,96 dengan $P$ Value lebih besar dari 0,05. Dapat disimpulkan bahwa family-work conflict tidak memberikan pengaruh terhadap job satisfaction.

\section{H2: Family-Work Conflict memberikan pengaruh negatif dan signifikan terhadap Work Engagement.}

Berdasarkan hasil uji hipotesis pada Tabel 4, dapat diketahui bahwa variabel family-work conflict terhadap work engagement memiliki nilai T Statistik sebesar 4,435 dengan nilai $P$ Value sebesar 0,000 , maka $H 2$ diterima karena nilai T Statistik lebih besar dari nilai $\mathrm{T}$ Tabel yaitu sebesar 1,96 dengan $P$ Value lebih kecil dari 0,05. Dapat disimpulkan bahwa family-work conflict memberikan pengaruh negatif dan signifikan terhadap work engagement.

\section{H3: Work Engagement memberikan pengaruh negatif dan signifikan terhadap Job Satisfaction.}

Berdasarkan hasil uji hipotesis pada Tabel 4, dapat diketahui bahwa variabel work engagement terhadap job satisfaction memiliki nilai T Statistik sebesar 7,094 dengan nilai $P$ Value sebesar 0,000 , maka $H 3$ diterima karena nilai T Statistik lebih besar dari nilai $\mathrm{T}$ Tabel yaitu sebesar 1,96 dengan $P$ Value lebih kecil dari 0,05. Dapat disimpulkan bahwa work engagement memberikan pengaruh negatif dan signifikan terhadap job satisfaction.

\section{H4: Work Engagement memediasi pengaruh Family-Work Conflict terhadap Job Satisfaction.}

Berdasarkan hasil uji hipotesis pada Tabel 4, dapat diketahui bahwa efek antara family-work conflict, work engagement, dan job satisfaction memiliki nilai T Statistik sebesar 3,687 dengan nilai $P$ Value sebesar 0,000. Dengan ini, H4 diterima karena memiliki nilai T Statistik yang lebih besar dari nilai T Tabel yaitu sebesar 1,96 dengan $P$ Value yang lebih kecil dari 0,05. Dapat disimpulkan bahwa work engagement memediasi pengaruh family-work conflict terhadap job satisfaction. 


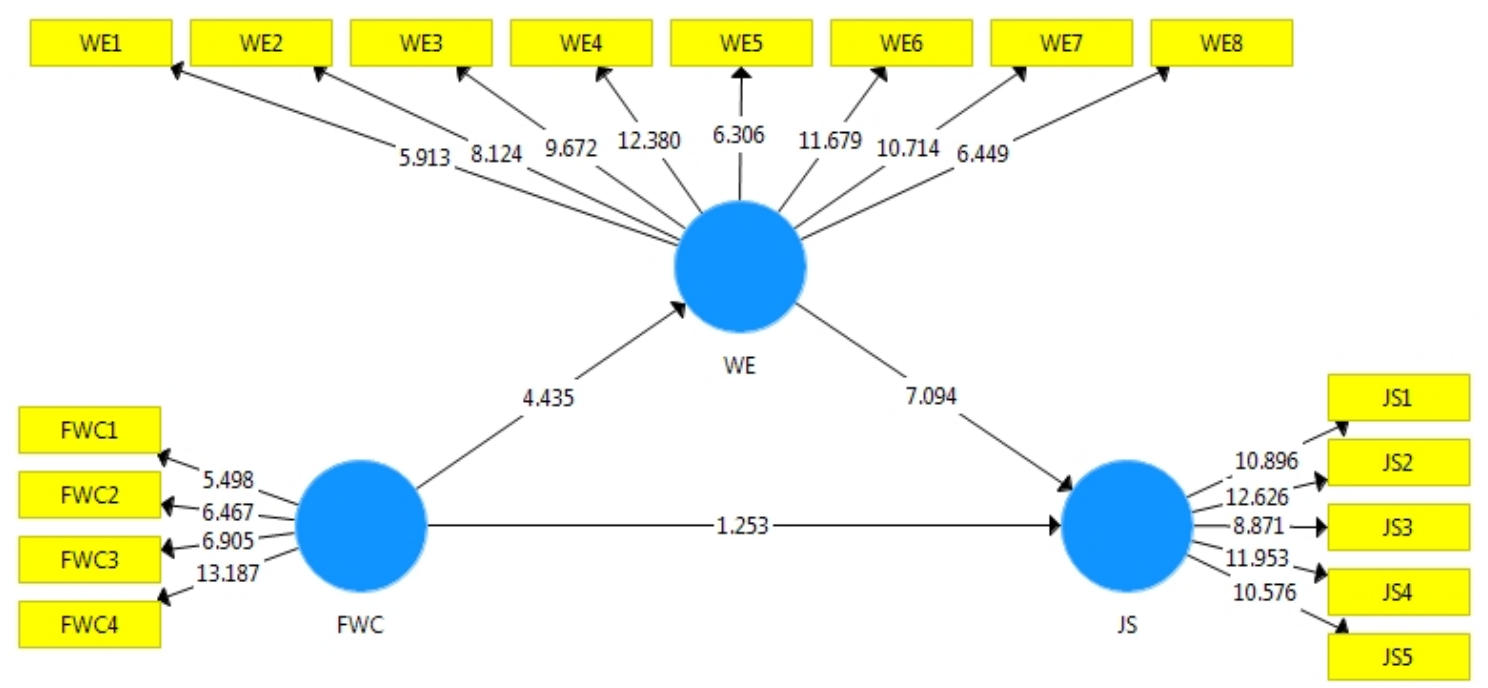

Sumber: Output Smart PLS 3

Gambar 3. Uji Hipotesis

\section{DISKUSI}

Hasil uji hipotesis pertama (H1) mengenai family-work conflict memberikan pengaruh negatif dan signifikan terhadap job satisfaction ditolak. Dapat disimpulkan bahwa family-work conflict tidak memberikan pengaruh terhadap job satisfaction. Hal ini didukung dengan adanya hasil penelitian yang dilakukan oleh Chung et al. (2012), Mihelič (2014), dan Bhalla dan Kang (2019) yang mengungkapkan bahwa family-work conflict tidak memiliki hubungan negatif yang signifikan terhadap job satisfaction. Chung et al. (2012) mengungkapkan bahwa alasan yang menyebabkan family-work conflict tidak memberikan pengaruh terhadap job satisfaction mungkin terletak pada perbedaan konflik yang dihadapi oleh tenaga penjualan Business to Business (B2B) dan karyawan ritel. Penjualan B2B lebih berbasis hubungan dan mungkin membutuhkan tenaga penjualan B2B untuk menginvestasikan lebih banyak waktu dan emosi pribadi. Oleh karena itu, ketika tenaga penjualan B2B harus memadukan tugas kerja dengan tugas keluarga, konflik mungkin menjadi lebih kuat secara emosional. Meskipun posisi karyawan ritel mungkin membutuhkan tenaga mingguan kerja yang lebih lama, konflik mungkin kurang kuat secara emosional dan, dengan demikian, memiliki dampak yang lebih kecil pada job satisfaction. Mihelič (2014) mengungkapkan bahwa tampaknya penilaian karyawan terhadap job satisfaction tidak dipengaruhi oleh pikiran, suasana hati dan perasaan yang berasal dari keluarga. Hal tersebut menjelaskan bahwa karyawan cenderung tidak menghiraukan urusan pribadi atau keluarga dengan pekerjaan mereka masing-masing. Penelitian ini juga mengungkapkan bahwa family-work conflict secara tidak langsung memiliki hubungan dengan job satisfaction.

Hasil uji hipotesis kedua (H2) mengenai family-work conflict memberikan pengaruh negatif dan signifikan terhadap work engagement diterima. Dapat disimpulkan bahwa family-work conflict dapat memberikan pengaruh negatif dan signifikan terhadap work engagement. Hal ini didukung dengan penelitian yang dilakukan oleh Karatepe dan Karadas (2016) dan juga Islam et al. (2019) yang mengungkapkan bahwa family-work 
conflict memiliki dampak negatif yang signifikan terhadap work engagement. Secara sederhana, hal ini dapat dijelaskan bahwa karyawan dapat menyeimbangkan mengenai urusan antara pekerjaan dan kehidupan keluarga mereka sehingga work engagement pada pekerjaan mereka tetap melekat. Lebih lanjut, adanya family-work conflict yang tinggi akan menurunkan work engagement terhadap pekerjaan yang mereka lakukan. Sebagai contoh, suatu keluarga yang sedang melalui masalah dengan keluarga mereka akan mengakibatkan mereka tidak fokus dalam mengerjakan pekerjaan mereka, sehingga dapat menurunkan semangat kerja, dedikasi terhadap pekerjaan, serta menjadi lebih sensitif terhadap lingkungan kerja atau dapat dikatakan lebih mudah marah terhadap hal-hal yang muncul secara tiba-tiba dalam pekerjaan mereka.

Hasil uji hipotesis ketiga (H3) mengenai work engagement memberikan pengaruh positif dan signifikan terhadap job satisfaction diterima. Dapat disimpulkan bahwa work engagement dapat memberikan pengaruh positif dan signifikan terhadap job satisfaction. Hal ini didukung dengan penelitian yang dilakukan oleh Yeh (2013) dan Ghosh et al. (2019) yang mengungkapkan bahwa work engagement mempunyai hubungan positif yang signifikan dengan job satisfaction. Hal ini disebabkan karena semakin tinggi work engagement pada karyawan, hal tersebut akan diikuti oleh kenaikan pada job satisfaction mereka. Karyawan yang memiliki work engagement terhadap pekerjaan mereka akan merasa bahwa mereka memiliki koneksi emosional tersendiri dengan pekerjaan yang mereka lakukan. Hasil dari penelitian ini juga memberikan bukti bahwa karyawan yang terikat dalam pekerjaan mereka memungkinkan untuk memiliki peluang yang lebih besar dalam tercapainya job satisfaction pada masing-masing karyawan atau pekerja.

Hasil uji hipotesis ketempat (H4) mengenai work engagement memediasi pengaruh family-work conflict terhadap job satisfaction diterima. Dapat disimpulkan bahwa work engagement dapat memediasi pengaruh family-work conflict terhadap job satisfaction. Dalam hasil penelitian ini, terbukti bahwa family-work conflict tidak memiliki pengaruh terhadap job satisfaction pada PT Matahari Department Store Tbk Mal Ciputra Jakarta, akan tetapi setelah variabel work engagement ditambahkan ke dalam model penelitian, variabel work engagement terbukti mampu memberikan korelasi antara family-work conflict terhadap job satisfaction.

\section{PENUTUP}

Berdasarkan hasil penelitian yang telah dilakukan dengan keterbatasan yang ada, terdapat beberapa saran yang diajukan. Variabel family-work conflict memiliki indikator paling tinggi pada pernyataan "stres di rumah membuat saya mudah marah di tempat kerja" dan paling rendah pada pernyataan "banyaknya tanggung jawab di rumah mengurangi waktu saya di tempat kerja". Dapat disimpulkan bahwa perusahaan sudah memberikan pekerjaan yang tepat pada karyawan sehingga pekerjaan yang ada di tempat kerja tidak perlu dibawa hingga ke rumah mereka masing-masing sehingga tidak akan menggaggu aktivitas yang ada di rumah mereka, akan tetapi, perusahaan hendaknya perlu meninjau kembali mengenai tanggung jawab mereka sebagai anggota keluarga yang mungkin akan mengurangi kepuasan kerja yang mereka miliki karena harus memikirkan hal yang harus dilakukan di rumah dan di tempat kerja agar selalu optimal. Variabel work engagement memiliki indikator paling tinggi pada pernyataan "saya bangga dengan pekerjaan yang saya lakukan" dan paling rendah pada pernyataan "saya terbenam dalam pekerjaan saya". 
Dapat disimpulkan bahwa karyawan memiliki keterikatan dalam pekerjaan yang mereka lakukan, hal itu terbukti dengan adanya kebanggaan tersendiri dalam menjalankan pekerjaan mereka yang akan membuat mereka terus bekerja dengan nyaman karena mereka sudah mempunyai pikiran positif terhadap pekerjaan yang mereka jalankan, akan tetapi, perusahaan hendaknya perlu meninjau kembali mengenai karyawan yang tidak terlalu menikmati pekerjaan mereka karena hal tersebut akan menyebabkan turunnya kepuasan kerja terhadap apa yang mereka lakukan. Jika hal tersebut terjadi, maka pekerjaan yang mereka hasilkan tidak optimal atau bahkan tidak mencapai target yang telah ditetapkan. Variabel job satisfaction memiliki indikator paling tinggi pada pernyataan "saya menemukan kesenangan dalam menjalankan pekerjaan saya" dan paling rendah pada pernyataan "hampir setiap hari saya antusias dengan pekerjaan saya". Dapat disimpulkan bahwa karyawan menikmati pekerjaan yang mereka miliki di tempat kerja karena mereka memiliki kesenangan atau kebanggaan tersendiri dalam menjalankan pekerjaan mereka, hal ini sejalan dengan variabel work engagement yang sebelumnya telah dibahas. Akan tetapi, hendaknya perlu ditinjau kembali mengenai antusias pekerjaan karyawan yang tidak timbul setiap hari. Hal ini mungkin akan dianggap normal karena karyawan juga membutuhkan istirahat pada akhir pekan sehingga tidak setiap hari mereka antusias dengan pekerjaan yang mereka lakukan melainkan hanya pada hari-hari tertentu selama mereka hadir untuk bekerja.

\section{DAFTAR PUSTAKA}

Abdurrahman, D., Fadilah, S. and Suarsih, S. (2010) 'Hubungan Konflik KeluargaPekerjaan dengan Kepuasan Kerja dan Niat Keluar Kerja', Mimbar, XXVI(1), pp. 115.

Bhalla, A. and Kang, L. S. (2019) 'Domain-specific and nonspecific outcomes of workfamily interface: A study of Indian journalists', Evidence-based HRM, 7(2), pp. 127142. doi: 10.1108/EBHRM-10-2017-0053.

Choi, H. J. and Kim, Y. T. (2010) 'Work-family conflict, work-family facilitation, and job outcomes in the Korean hotel industry', International Journal of Contemporary Hospitality Management, 24(7), pp. 1-5.

Chung, T. L., Rutherford, B. and Park, J. (2012) 'Understanding multifaceted job satisfaction of retail employees', International Journal of Retail and Distribution Management, 40(9), pp. 699-716. doi: 10.1108/09590551211255974.

Ghosh, P., Jawahar, I. M. and Rai, A. (2019) 'Do men and women experience work engagement and job satisfaction to the same extent in collectivistic, patriarchal societies?', International Journal of Manpower. doi: 10.1108/IJM-11-2018-0378.

Griffin, M. L. et al. (2010) 'Job involvement, job stress, job satisfaction, and organizational commitment and the burnout of correctional staff', Criminal Justice and Behavior, 37(2), pp. 239-255. doi: 10.1177/0093854809351682.

Hair, J. F. et al. (2014) Multivariate Data Analysis (MVDA). 7th edn, Pharmaceutical Quality by Design: A Practical Approach. 7th edn. Harlow, England: Pearson Education Limited. doi: 10.1002/9781118895238.ch8.

Hair Jr, J. F. et al. (2014) 'Partial least squares structural equation modeling (PLS-SEM): An emerging tool in business research', Practical Assessment, Research and Evaluation, 26(2), pp. 106-121. doi: 10.1108/ebr-10-2013-0128.

Islam, T. et al. (2019) 'Police work-family nexus, work engagement and turnover intention: Moderating role of person-job-fit', Policing, 42(5), pp. 739-750. doi: 


\subsection{8/PIJPSM-09-2018-0138.}

Karatepe, O. M. and Karadas, G. (2016) 'Service employees' fit, work-family conflict, and work engagement', Journal of Services Marketing, 30(5), pp. 554-566. doi: 10.1108/JSM-02-2015-0066.

Mihelič, K. K. (2014) 'Work-family interface, job satisfaction and turnover intention: A CEE transition country perspective', Baltic Journal of Management, 9(4), pp. 446466. doi: 10.1108/BJM-09-2013-0141.

Netemeyer, R. G., Boles, J. S. and McMurrian, R. (1996) 'Development and validation of work-family conflict and family-work conflict scales', Journal of Applied Psychology, 81(4), pp. 400-410. doi: 10.1037/0021-9010.81.4.400.

Rotondo, D. M. and Kincaid, J. F. (2008) 'Conflict, facilitation, and individual coping styles across the work and family domains', Journal of Managerial Psychology, 23(5), pp. 484-506. doi: 10.1108/02683940810884504.

Schaufeli, W. B., Bakker, A. B. and Salanova, M. (2006) 'The measurement of work engagement with a short questionnaire: A cross-national study', Educational and Psychological Measurement, 66(4), pp. 701-716. doi: 10.1177/0013164405282471.

Singh, R. and Nayak, J. K. (2015) 'Mediating role of stress between work-family conflict and job satisfaction among the police officials: Moderating role of social support', Policing, 38(4), pp. 738-753. doi: 10.1108/PIJPSM-03-2015-0040.

Yeh, C. M. (2013) 'Tourism involvement, work engagement and job satisfaction among frontline hotel employees', Annals of Tourism Research. Elsevier Ltd, 42, pp. 214239. doi: 10.1016/j.annals.2013.02.002. 